\title{
Thermally activated delayed fluorescence material- sensitized helicene enantiomer-based OLEDs: a new strategy for improving the efficiency of circularly polarized electroluminescence
}

\author{
Meng $\mathrm{Li}^{{ }^{*}}$, Yin-Feng Wang ${ }^{1,2}$, Da-Wei Zhang ${ }^{1,2}$, Dongdong Zhang ${ }^{3^{*}}$, Zhi-Qiang Hu ${ }^{4}$, \\ Lian Duan ${ }^{3}$ and Chuan-Feng Chen ${ }^{1,2^{*}}$
}

\begin{abstract}
A new strategy of thermally activated delayed fluorescence (TADF) material-sensitized circularly polarized luminescence (CPL) has been proposed for improving the efficiencies of fluorescent circularly polarized organic lightemitting diodes (OLEDs) (CP-OLEDs). Consequently, a pair of helicene enantiomers, $(P)$-HAI and $(M)$-HAI, were synthesized. The helicene enantiomers with the rigid helical $\pi$ skeleton had highly thermal and enantiomeric stabilities, and they also showed excellent photophysical properties, especially, intense mirror-image CPL activities with large luminescence dissymmetry factor $\left(\left|g_{\text {lum }}\right|\right)$ values of about $6 \times 10^{-3}$. Notably, the CP-OLEDs with the helicene enantiomers as emitters and a TADF molecule as sensitizer not only displayed better performance of lower turn-on voltage $\left(V_{\mathrm{T}}\right)$ of $2.6 \mathrm{~V}$, four-fold maxmium-external quantum efficiency $\left(\mathrm{EQE}_{\mathrm{max}}\right)$ of $5.3 \%$, and lower efficiencies roll-off of $1.9 \%$ at $1000 \mathrm{~cd} \mathrm{~m}^{-2}$, than those of the devices without TADF sensitizer, but also exhibited intense circularly polarized electroluminescence (CPEL) with the electroluminescence dissymmetry factor $\left(g_{\mathrm{EL}}\right)$ values of $-2.3 \times 10^{-3}$ and $+3.0 \times 10^{-3}$. Meanwhile, this study also represents the first thermally activated sensitized fluorescent CP-OLEDs with markedly enhanced efficiencies and intense CPEL.
\end{abstract}

Keywords: thermally activated sensitized emission, helicene, electroluminescence, circularly polarized light, organic lightemitting diodes

\section{INTRODUCTION}

Organic light-emitting diode (OLED) with chiral luminophore as emitter is the most prospective method to directly emit circularly polarized electroluminescence (CPEL) for the simple device architectures and unique technological merits [1], which can not only reduce energy loss caused by the use of polarizers, but also has important application prospects in future display and photon technology [2-4], such as three-dimensional (3D) display, optical communication and data storage. Since Meijer's group [5] reported the first circularly polarized OLED (CP-OLED) using chiral polymer as emitter, the strategy of obtaining CPEL based on CP-OLED has attracted extensive attention and developed rapidly [6-16]. Especially, CP-OLEDs based on chiral fluorescent emitters could not only successfully achieve the CPEL [1719], but also have the advantages of long device lifetime, good stability and low efficiency roll-off. Moreover, chiral fluorescent molecules with CPL activities are also cheap and easily available [20-23]. However, the devices based on fluorescent emitters generally suffer low efficiencies for only $25 \%$ exciton utilization of the fluorophores (Fig. 1a) [24,25]. To date, the highest external quantum efficiency (EQE) of CP-OLED based on conventional chiral fluorescent molecules is $3.09 \%$ [18], and thus the low efficiencies of fluorescent CP-OLEDs would inevitably limit their practical applications. Therefore, how

\footnotetext{
${ }^{1}$ Beijing National Laboratory for Molecular Sciences, CAS Key Laboratory of Molecular Recognition and Function, Institute of Chemistry, Chinese Academy of Sciences, Beijing 100190, China

${ }^{2}$ University of Chinese Academy of Sciences, Beijing 100049, China

${ }^{3}$ Department of Chemistry, Tsinghua University, Beijing 100084, China

${ }^{4}$ College of Chemistry and Molecular Engineering, Qingdao University of Science and Technology, Qingdao 266042, China

* Corresponding authors (emails: limeng@iccas.ac.cn (Li M); ddzhang@mail.tsinghua.edu.cn (Zhang D); cchen@iccas.ac.cn (Chen CF))
} 

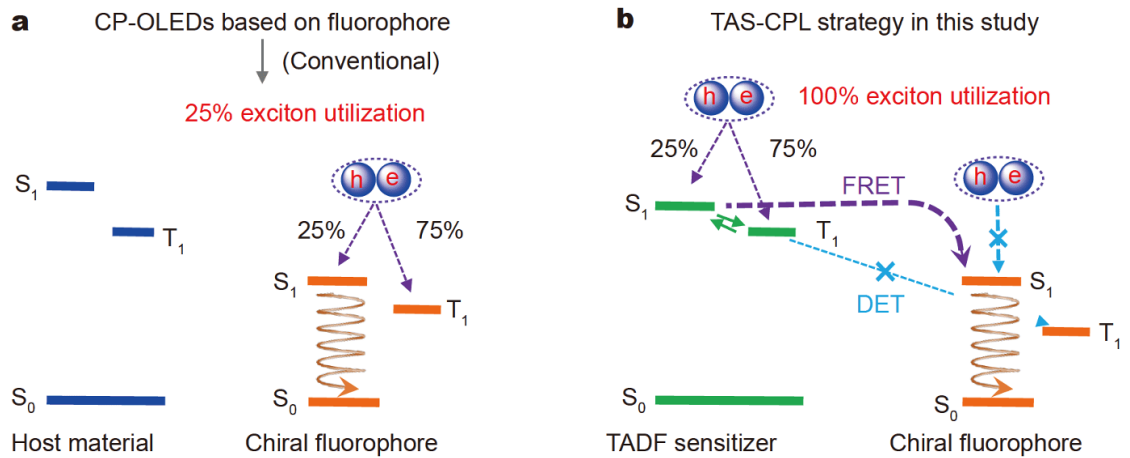

Figure 1 (a) Reported CP-OLEDs based on chiral fluorophore, and (b) new strategy of TAS-CPL for efficient CP-OLEDs.

to improve the efficiencies of fluorescent CP-OLEDs is a key issue to be addressed urgently.

Recently, a new kind of chiral emitters with both thermally activated delayed fluorescence (TADF) and circularly polarized luminescence (CPL) properties have been developed [26-28]. Since we reported the first TADF-based CP-OLED with high EQEs in 2018 [29], the fabrication of CP-OLEDs by using chiral TADF molecules as the emitters has become a prospective strategy to obtain efficient CPEL [30-35]. However, the reported chiral TADF molecules were only used as emitters in the devices, and the emitters were also required to have small singlet-triplet gap $\left(\Delta E_{\mathrm{ST}}\right)$, large luminescence dissymmetry factor $\left(g_{\text {lum }}\right)$, high racemic energy barrier and high mobility, simultaneously, which results in the difficulty of their design and synthesis. Since the conventional chiral fluorescent molecules are easily available, it is significant to develop a new strategy for conveniently constructing efficient CP-OLEDs based on the conventional chiral fluorophores without TADF properties.

On the basis of TADF material-sensitized (TAS) emission mechanism [36-38], we herein report a new strategy of TADF material-sensitized CPL (TAS-CPL) for constructing efficient CP-OLEDs, with TADF material as the sensitizer to improve exciton utilization, and chiral fluorophore as the emitter to ensure CPEL activity. As illustrated in Fig. 1b, the ideal TAS-CPL process is that the exciton only recombined on the TADF sensitizer, and the singlet $\left(S_{1}\right)$ energy is promoted through an efficient reverse intersystem crossing (RISC) process, then the $S_{1}$ energy will be transferred to the chiral fluorophore through fluorescence resonance energy transfer (FRET), so as to emit efficient CPEL. Thus, the core of the TASCPL strategy is to design chiral emitters, which not only match the energy levels of TADF sensitizer to improve the efficiencies, but also have intense CPL activities. He- licenes are a kind of polycyclic aromatic hydrocarbons with helical chirality [39]. Their unique helical structures and specific photoelectric properties make them become one of the most attractive chiral fluorescent molecules in recent years [40-45]. Although helicene enantiomers with circularly polarized photoluminescence (CPPL) of high $g_{\text {lum }}$ values have attracted increasing interest and become one of the hottest topics in CPL materials [46], the CPEL of helicene enantiomers lag significantly behind. Moreover, helicenes usually suffer from difficult synthesis, easy racemization, and low quantum yield. Thus, designing helicene enantiomers with high $g_{\text {lum }}$ values and utilizing TAS-CPL strategy to improve exciton utilization (up to $100 \%$ ), might be the most efficient method to achieve efficient CP-OLEDs.

In this study, a pair of helicene enantiomers $(P)$-HAI and (M)-HAI (Fig. 2a) were obtained conveniently by a three-step reaction as well as enantiomeric resolution. Since the helicene has a rigid helical $\pi$-skeleton, its enantiomers possess not only highly enantiomeric stability, but also excellent photophysical properties, especially, intense CPL activities with large $\left|g_{\text {lum }}\right|$ values of about $6 \times$ $10^{-3}$. Moreover, the helicene-based CP-OLEDs with TADF sensitizer not only displayed better performance of lower turn-on voltage $\left(V_{\mathrm{T}}\right)$ of $2.6 \mathrm{~V}$, four-fold $\mathrm{EQE}_{\max }$ of $5.3 \%$, and lower efficiencies roll-off of only $1.9 \%$ at $1000 \mathrm{~cd} \mathrm{~m}^{-2}$, than those of the devices without TADF

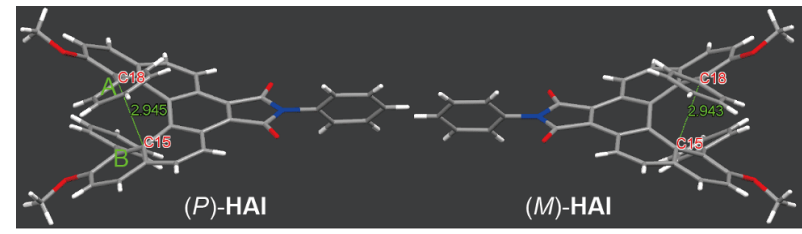

Figure 2 Crystal structures of the helicene enantiomers $(P)$-HAI (left) and $(M)$-HAI (right). 
sensitizer, but also exhibited intense CPEL with the electroluminescence (EL) dissymmetry factor $\left(g_{\mathrm{EL}}\right)$ values of $-2.3 \times 10^{-3}$ and $+3.0 \times 10^{-3}$, which represents the first TAS fluorescent CP-OLEDs with markedly improved efficiencies and intense CPEL.

\section{EXPERIMENTAL SECTION}

\section{General methods}

All the reagents and solvents were commercially available and used without further purification. ${ }^{1} \mathrm{H}$ and ${ }^{13} \mathrm{C}$ nuclear magnetic resonance (NMR) spectra were recorded on Brucker ${ }^{\circledR}$ AVIII $500 \mathrm{MHz}$ NMR spectrometers. High resolution mass spectra (HR-MS) were obtained on the Thermo Fisher Exactive high-resolution LC-MS spectrometer. High performance liquid chromatography (HPLC) analysis and resolution were performed on an Agilent 1260 Infinity. Analytical injections were performed on chiral stationary phase using the column (Chiralpak ${ }^{\bullet} \mathrm{IE}, 4.6 \mathrm{~mm} \times 250 \mathrm{~mm}$ ) and the mobile phase of hexane and dichloromethane. Single crystal data were collected on a Bruker Smart APEXII CCD diffractometer using graphite monochromated $\mathrm{Cu} \mathrm{Ka}$ radiation. The UV-vis spectra were recorded on a PerkinElmer ${ }^{\circ} \mathrm{UV} / \mathrm{Vis} /$ NIR spectrometer (Lambda 950), and the fluorescence spectra and transient photoluminance decay characteristics were measured using an Edinburgh Instruments FLS1000 spectrometer. The optical rotation was determined by a Rudolph Autopol VI Automatic polarimeter. Circular dichroism (CD) spectra were recorded on a JASCO J810 spectropolarimeter. CPL and CPEL spectra were performed with a JASCO CPL-300 spectrometer at room temperature.

\section{Synthesis of compound 2}

Maleic anhydride ( $4.9 \mathrm{~g}, 50 \mathrm{mmol}, 5.0$ equiv) was added to a solution of diene $1(4.7 \mathrm{~g}, 10 \mathrm{mmol})$ in xylene $(40 \mathrm{~mL})$ with vigorous stirring, followed by reflux for $3 \mathrm{~h}$. After the reaction mixture was cooled to room temperature, the solvent was removed by rotatory evaporation to give crude product, which was further purified by recrystallization in acetic acid to give compound $2(4.6 \mathrm{~g}$, $81 \%)$ as white powder. ${ }^{1} \mathrm{H}$ NMR $\left(500 \mathrm{MHz}, \mathrm{CDCl}_{3}\right) \delta$ 7.12-7.03 (m, 4H), 7.02-6.91 (m, 2H), 6.80-6.64 (m, 4H), 6.50-6.43 (m, 4H), $3.57(\mathrm{~d}, J=13.1 \mathrm{~Hz}, 6 \mathrm{H}), 3.02-2.90$ (m, 2H), 2.82-2.79 (m, 1H), 2.53-2.31 (m, 3H), 2.20-2.16 (m, 1H), 2.00-1.97 (m, 1H), 1.47-1.23 (m, 3H), 1.09-0.97 $(\mathrm{m}, 1 \mathrm{H}) .{ }^{13} \mathrm{C}$ NMR $\left(126 \mathrm{MHz}, \mathrm{CDCl}_{3}\right) \delta 172.8,172.0$, $155.6,155.5,137.6,137.4,137.2,136.9,135.5,134.5,134.0$, $133.2,130.8,130.5,130.4,130.2,129.4,129.3,127.79$,
$127.77,127.4,127.1,126.8,126.5,125.6,125.4,110.7$, $110.6,56.24,56.22,45.5,44.4,40.4,38.5,30.3,27.3,26.8$, 25.9. HR-MS (APCI): $m / z$ calcd. for $\mathrm{C}_{38} \mathrm{H}_{33} \mathrm{O}_{5}[\mathrm{M}+\mathrm{H}]^{+}$ 569.2323 , found 569.2346 .

\section{Synthesis of rac-HAI}

A mixture of $2(0.57 \mathrm{~g}, 1.0 \mathrm{mmol})$, palladium-charcoal (Pd $10 \mathrm{wt} \%)(0.5 \mathrm{~g})$, and sulphur $(1.5 \mathrm{~g})$ was heated at $300^{\circ} \mathrm{C}$ for $15 \mathrm{~min}$. On cooling, dichloromethane $(5 \times 30 \mathrm{~mL})$ was added to extract the crude products. Without further purification, the obtained crude product with aniline $(0.28 \mathrm{~g}, 3.0 \mathrm{mmol})$ in acetic acid $(30 \mathrm{~mL})$ was stirred by reflux for $3 \mathrm{~h}$. After the reaction mixture was cooled to room temperature, the organic solvent was removed in vacum, and the residue was purified by flash column chromatography with dichloromethane and petroleum ether $(2: 1, v / v)$ as eluent to give the compound rac-HAI $(0.33 \mathrm{~g}, 52 \%)$ as orange-red solid. $R_{\mathrm{f}}=0.44$. Melting point $(\mathrm{mp})>280^{\circ} \mathrm{C} .{ }^{1} \mathrm{H}$ NMR $\left(500 \mathrm{MHz}, \mathrm{CDCl}_{3}\right)$ $\delta 8.60(\mathrm{~d}, J=8.5 \mathrm{~Hz}, 2 \mathrm{H}), 7.63-7.52(\mathrm{~m}, 6 \mathrm{H}), 7.45-7.41$ $(\mathrm{m}, 3 \mathrm{H}), 7.29(\mathrm{~d}, J=8.9 \mathrm{~Hz}, 2 \mathrm{H}), 6.85(\mathrm{td}, J=7.6,1.4 \mathrm{~Hz}$, $2 \mathrm{H}), 6.77-6.73(\mathrm{~m}, 4 \mathrm{H}), 6.37(\mathrm{td}, J=7.6,1.4 \mathrm{~Hz}, 2 \mathrm{H}), 5.40$ $(\mathrm{dt}, J=7.8,1.5 \mathrm{~Hz}, 2 \mathrm{H}), 3.70(\mathrm{~s}, 6 \mathrm{H}) .{ }^{13} \mathrm{C}$ NMR $(126 \mathrm{MHz}$, $\left.\mathrm{CDCl}_{3}\right) \delta 168.8,155.9,136.3,132.1,131.5,130.23,130.17$, $130.09,129.3,129.2,129.1,127.8,127.3,127.2,126.9$, $126.57,126.56,126.1,124.8,117.6,113.9,56.9$. HR-MS (APCI): $m / z$ calcd. for $\mathrm{C}_{44} \mathrm{H}_{30} \mathrm{NO}_{4}[\mathrm{M}+\mathrm{H}]^{+}$636.2169, found 636.2175 .

\section{Enantiomeric resolution of the helicene enantiomers}

HPLC with chiral column has been used in enantiomeric resolution of rac-HAI to obtain the enantiomers $(P)$-HAI and $(M)$-HAI. The injections were performed on chiral stationary phase using the column (Chiralpak ${ }^{\odot} \mathrm{IE}$, $4.6 \mathrm{~mm} \times 250 \mathrm{~mm}$ ) and the mobile phase of hexane/dichloromethane $(50 / 50, v / v)$ with flow rate of

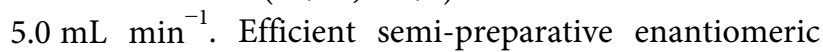
resolution of rac-HAI was performed by HPLC (Figs S1S3), which provided the pair of enantiomers $(P)$-HAI and (M)-HAI (enantiomeric excess (ee) $>99 \%$ ) in gram scale.

\section{Device fabrication and measurements}

The pre-coated indium tin oxide (ITO) glass substrates were cleaned with Decon 90, rinsed in ultrapure water and ethanol, dried in a infrared drying oven at $120^{\circ} \mathrm{C}$, then by plasma cleaning process. After pre-treatment of the substrates, the devices were fabricated by vacuum deposition onto the substrates for organic and metal deposition successively with rate of $1-2 \AA s^{-1}$. The currentvoltage-luminance characteristics and $\mathrm{EL}$ of the devices 
were measured with a computer-controlled Spectrascan PR 670 spectrophotometer and Keithley 2400 SourceMeter.

\section{RESULTS AND DISCUSSION}

\section{Synthesis and enantiomeric resolution}

The helicene rac-HAI used in this study was conveniently synthesized by a three-step reaction of Diels-Alder addition, dehydroaromatization, as well as lactamization (Scheme 1), and also fully characterized by ${ }^{1} \mathrm{HNMR}$, ${ }^{13}$ CNMR and MS (see the Supplementary information for details). Subsequently, the helicene enantiomers $(P)$-HAI and $(M)$-HAI with ee values of up to $99 \%$ were obtained on a gram scale by enantiomeric resolution using HPLC with chiral column (Tables S1, S2). To verify whether the obtained enantiomers racemized during device fabrication, we tested their enantiomeric stability by HPLC. Benefiting from the sterically hindered phenyl at the 1,1'positions of helicene, the helicene enantiomer possesses excellent enantiomeric stability, which displays no racemization even after multiple sublimation (ee > 99\%; Figs S4, S5; Table S3).

\section{Electrochemical measurement and theoretical calculations} The cyclic voltammetry was then performed to investigate the electrochemical properties of helicene enantiomers (Fig. S6). Determined from the anodic oxidation potential of $(P)$-HAI, the highest occupied molecular orbit (HOMO) energy level of the enantiomer was calculated to be $-5.65 \mathrm{eV}$. The energy gap $\left(E_{\mathrm{g}}\right)$ was determined to be $2.29 \mathrm{eV}$ from the onset of the absorption spectra of the helicene, and the lowest unoccupied molecular orbit (LUMO) energy level of (P)-HAI was $-3.36 \mathrm{eV}$, which was calculated by the HOMO value and the $E_{\mathrm{g}}$ (Table S4). Besides, time-dependent density functional theory calculations were also performed to simulate the geometrical and electronic properties of helicenes (see the Supplementary information for details, Fig. S7). The electronic

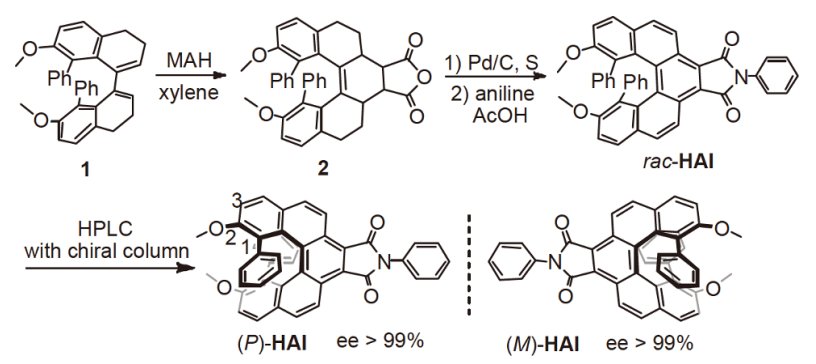

Scheme 1 Synthesis of rac-HAI and its enantiomeric resolution. distribution covered the whole helicene, the HOMO was mainly dispersed on the helical skeleton, and the LUMO was more likely to be distributed in the carbonyl groups. The slightly spatial electronic separation of HOMOLUMO ensure the helicenes to have excellent $\mathrm{CD}$ and CPL activities.

\section{Single crystal structure analysis}

By slow evaporation of the solution of the obtained enantiomer in a mixture of petroleum ether and dichloromethane $(1: 1, v / v)$, single crystals suitable for X-ray diffraction (XRD) analysis were obtained. As shown in Fig. 2, both $(P)$-HAI and $(M)$-HAI are featured with crystal structures, and their absolute configurations were confirmed by the corresponding crystal structures. The single crystal structures display helical skeleton with dihedral angle of about $50^{\circ}$, which could effectively prevent the fluorescence quenching in solid state. Additionally, the helicenes not only have intermolecular hydrogen bonds and $\pi-\pi$ interactions (Figs S8, S9; Tables S5, S6), but also might have intramolecular $\pi-\pi$ interactions. As shown in Fig. 2, the phenyl (A) group at 1-position of helicene is only about $2.945 \AA$ from the aromatic ring (B) of the helicene skeleton, which is short enough for energy transfer, and thus results in long-wavelength absorption.

\section{Thermal properties}

The helicenes also possess excellent thermal stabilities with decomposition temperature $\left(T_{\mathrm{d}}\right)$ of $408^{\circ} \mathrm{C}$ and glasstransition temperature $\left(T_{\mathrm{g}}\right)$ of $316^{\circ} \mathrm{C}$ (Figs S10, S11). The thermal and enantiomeric stabilities of the helicenes ensure that the high-performance CP-OELD can be constructed by vapor deposition.

\section{Photophysical properties}

The photophysical properties of the helicenes were then investigated. Since the enantiomers $(P)$-HAI and $(M)$ HAI only have differences in chiral characteristics, their photophysical properties are almost identical. As shown in Fig. 3, both the enantiomers exhibit an obvious absorption band from 400 to $550 \mathrm{~nm}$, which can be attributed to their large $\pi$-conjugated skeleton. The absorption of the emitter with long wavelength is favorable for overlapping with the emission of TADF sensitizer. Moreover, the enantiomers exhibit an emission peak at $547 \mathrm{~nm}$, as well as relatively small Stokes shift. With the increase of the solvent polarity, the emission spectra of enantiomer $(P)$-HAI show a remarkable redshift from $528 \mathrm{~nm}$ (in hexane) to $585 \mathrm{~nm}$ (in dimethyl formamide (DMF)) (Fig. S12 and Table S7). Meanwhile, the quantum 


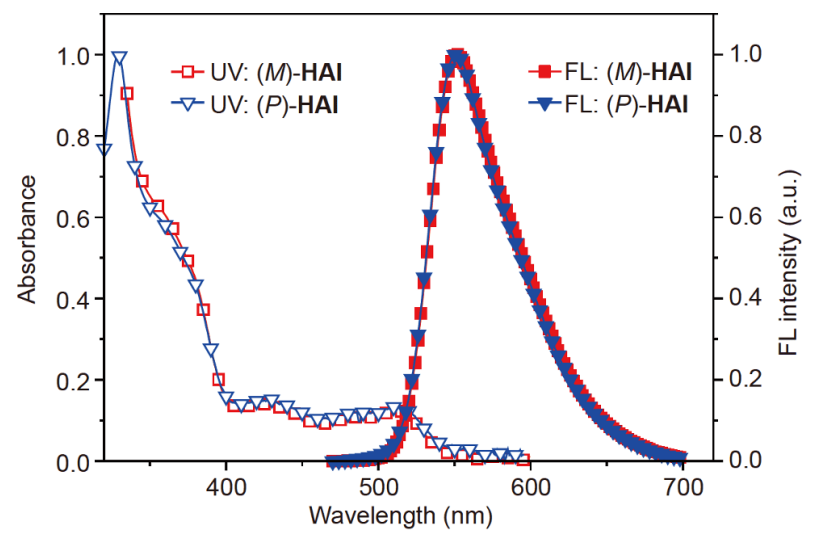

Figure 3 Absorption and fluorescence spectra of $(P)$-HAI and (M)-HAI in toluene $\left(c=1.0 \times 10^{-5} \mathrm{~mol} \mathrm{~L}^{-1}\right)$.

yield and fluorescent lifetime of the helicene enantiomer were subsequently measured in toluene to be 0.24 and $5.1 \mathrm{~ns}$, respectively (Figs S13, S14). Thus, the radiation transition rate $\left(\kappa_{\mathrm{r}}^{\mathrm{s}}\right)$ of the helicene is about $4.7 \times 10^{7}$ (Table S8). The luminescent properties of these helicene enantiomers are better than those of most reported helicenes [45].

To investigate the chiroptical properties of the helicene enantiomers, their specific rotation, CD and CPL activities were then tested. The specific rotation of $(P)$-HAI and $(M)$-HAI were measured to be $-161^{\circ}$ and $+160^{\circ}(c=$ $\left.1.0 \mathrm{mg} \mathrm{mL}^{-1}, \mathrm{CH}_{2} \mathrm{Cl}_{2}\right)$, respectively. As shown in Fig. $4 \mathrm{a}$, obvious mirror-image $\mathrm{CD}$ signals of the enantiomers were obscerved. For $(P)$-HAI, its CD signal displayed positive Cotton effect in short wavelength regions $(<467 \mathrm{~nm})$, and negative signal at its long absorption band. Comparatively, the CD signal of $(M)$-HAI was exactly opposite to that of $(P)$-HAI. The results indicate the helicene enantiomers show good chirality in the ground state. Moreover, CPL spectra of the helicenes were also recorded (Fig. 4b). Benefitting from the good

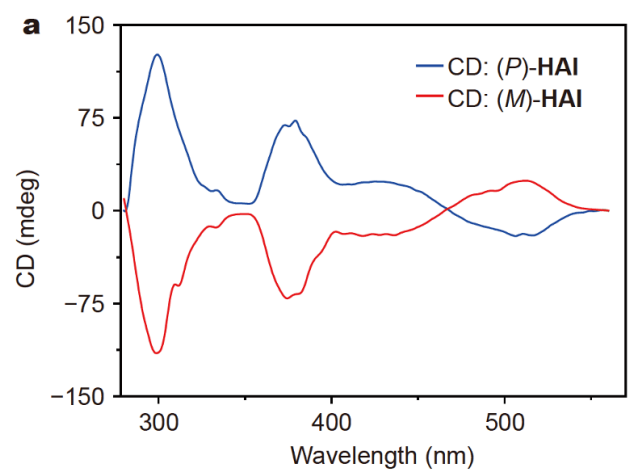

luminescent properties and the chirality in the excited state, the enantiomers exhibited perfect mirror-image CPL signals with the $g_{\text {lum }}$ values of $-5.9 \times 10^{-3}$ for $(P)$ HAI and $+6.2 \times 10^{-3}$ for $(M)$-HAI, respectively. The $g_{\text {lum }}$ values of the enantiomers with rigid helical skeleton are larger than those of the most chiral luminophores with other chiral elements $[20,21]$. Therefore, the helicene enantiomers might be excellent chiral emitter candidates for CP-OLEDs with intense CPEL activities.

To study the TAS-CPL process under optical excitation, DPhCzTrz (3-(3-(4,6-diphenyl-1,3,5-triazin-2-yl)phenyl)6,9-diphenyl-9H-carbazole) with wide energy gap and 4CzIPN (2,4,5,6-tetra(9H-carbazol-9-yl)-isophthalonitrile) with a small $\Delta E_{\mathrm{ST}}$ of $0.083 \mathrm{eV}$ were chosen as host and TADF sensitizer, respectively. As shown in Fig. S15, obvious overlaps between the absorption of $(P)$-HAI and the emission of 4CzIPN were observed, indicating efficient energy transfer can be anticipated. In the co-doped film, DPhCzTrz with wide energy gap was used as host to avoid the aggregation quenching of TADF materials, and the photoluminescence quantum yield (PLQY) of the codoped film was 0.33 . Increasing the concentration of $(P)$ or $(M)$-HAI, the emission band of 4CzIPN was sharply reduced. When the concentration of $(P)$ - or $(M)$-HAI was about $3 \mathrm{wt} \%$, only emission of the helicene enantiomer was visible, indicating efficient energy transfer between the sensitizer and the emitter occurred (Fig. S16). In addition, the helicenes had significant solvation effect, so in the polar host material of DPhCzTrz, their emission spectra dispalyed obvious red shift (Fig. 5a). Moreover, transient PL of the helicene in the co-doped film was also studied at $580 \mathrm{~nm}$. As shown in Fig. 5b, with the increase of the concentration of $(P)$ - or $(M)$-HAI, the lifetime and ratio of the delayed part of $4 \mathrm{CzIPN}$ were reduced gradually for its singlet energy being transferred to $(P)$ - or $(M)$-HAI through FRET. Meaningfully, the co-doped films also exhibited obvious CPL activities (Figs S17, S18),

Figure 4 (a) CD and (b) CPL spectra of (P)-HAI and (M)-HAI in toluene. 

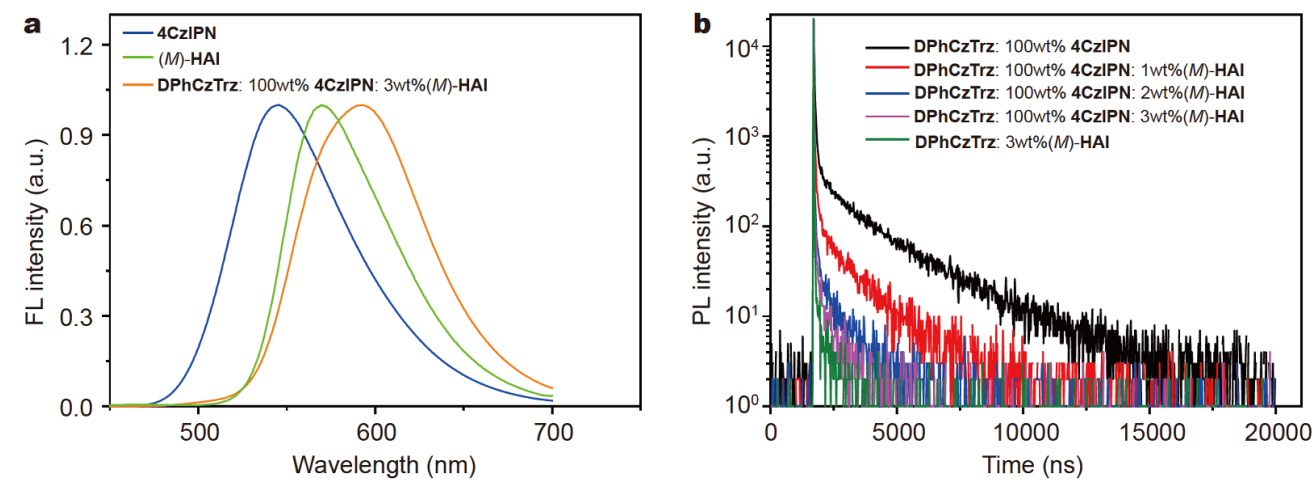

Figure 5 (a) Fluorescence spectra of 4CzIPN, (M)-HAI, and co-doped films of DPhCzTrz: 100 wt\% 4CzIPN: 3 wt\% (M)-HAI. (b) The transient PL decay curves of the DPhCzTrz:4CzIPN:(M)-HAI co-doped films observed at $580 \mathrm{~nm}$.

and a fraction of signals might have originated by energy transfer from the up-converted 4CzIPN triplets, which evidenced the TAS-CPL process under optical excitation.

\section{EL properties}

The EL performances of $(P)$-HAI and $(M)$-HAI were further studied by fabricating multilayer OLEDs. For the helicene-based OLEDs without TADF sensitizer (FLOLEDs), the co-doped film of DPhCzTrz with $3 \mathrm{wt} \%(P /$ $M$ )-HAI was used as emitting layers (EMLs). And for the helicene-based OLEDs with TADF sensitizer (TASOLEDs), the co-doped film of DPhCzTrz with $100 \mathrm{wt} \%$ 4CzIPN as TADF sensitizer and $3 \mathrm{wt} \%(P / M)$-HAI as emitter was used as EMLs. The multilayer OLEDs were fabricated with the following architecture: ITO/4,4'cyclohexylidenebis [ $N, N$-bis(4-methylphenyl)aniline] (TAPC) $(30 \mathrm{~nm}) / 4,4^{\prime}, 4^{\prime \prime}$-tris(carbazol-9-yl)-triphenylamine (TCTA) $(10 \mathrm{~nm}) / 1,3$-bis $(9 H$-carbazol-9-yl)benzene (mCP) $\quad(10 \mathrm{~nm}) /$ EML $\quad(30 \mathrm{~nm}) / 4,7-$ diphenyl-1,10-phenanthrolinesynonym (Bphen) $(30 \mathrm{~nm}) / \mathrm{LiF}(0.5 \mathrm{~nm}) / \mathrm{Al}$ $(150 \mathrm{~nm})$ (Fig. 6a). Since the properties of the two enantiomers were almost identical, the EL performance of the enantiomer-based devices were similar as well (see Fig. 6, Figs S19, S20, and Table 1).

For the FL-OLEDs, the $(P)$-HAI-based device emitted yellow EL centered at $570 \mathrm{~nm}\left(\lambda_{\mathrm{EL}}\right)$ with turn-on voltage $\left(V_{\mathrm{T}}\right)$ of $3.2 \mathrm{~V}$, maximum current efficiency $\left(\mathrm{CE}_{\max }\right)$ of $4.1 \mathrm{~cd} \mathrm{~A}^{-1}$, maximum power efficiency $\left(\mathrm{PE}_{\max }\right)$ of $3.4 \mathrm{~lm} \mathrm{~W}{ }^{-1}$, and maximum EQE of $1.3 \%$. Meanwhile, the EL performances of $(M)$-HAI-based device were similar to those of that based on $(P)$-HAI, which displayed $\lambda_{\mathrm{EL}}$ of $570 \mathrm{~nm}, V_{\mathrm{T}}$ of $3.4 \mathrm{~V}, \mathrm{CE}_{\max }$ of $4.1 \mathrm{~cd} \mathrm{~A}^{-1}$ and $\mathrm{PE}_{\max }$ of $3.5 \mathrm{~lm} \mathrm{~W}^{-1}, \mathrm{EQE}_{\max }$ of $1.2 \%$, respectively (Table 1 ). Meaningfully, compared with the above FL-OLEDs, TASOLEDs with TADF sensitizer displayed more efficient EL performances. As shown in Fig. 6, compared with $(P)$ HAI-based FL-OLED, (P)-HAI-based TAS-OLED exhibited $\lambda_{\mathrm{EL}}$ of $585 \mathrm{~nm}$, lower $V_{\mathrm{T}}$ of $2.6 \mathrm{~V}$, and four-fold $\mathrm{EQE}_{\max }$ of $5.3 \%$, as well as higher $\mathrm{CE}_{\max }$ of $15.1 \mathrm{~cd} \mathrm{~A}^{-1}$ and $\mathrm{PE}_{\max }$ of $11.3 \mathrm{~lm} \mathrm{~W} \mathrm{~m}^{-1}$. Intriguingly, the device also exhibited extremely low efficiency roll-off of 1.9\% (EQE = $5.2 \%)$ and $20.7 \%(\mathrm{EQE}=4.2 \%)$ at 1000 and $5000 \mathrm{~cd} \mathrm{~m}^{-2}$, respectively. Since the properties of the two enantiomers were almost identical, their EL characteristics were similar as well. And the (M)-HAI-based TAS-OLEDs displayed $\lambda_{\mathrm{EL}}$ of $585 \mathrm{~nm}, V_{\mathrm{T}}$ of $2.8 \mathrm{~V}, \mathrm{CE}_{\max }$ of $14.5 \mathrm{~cd} \mathrm{~A}^{-1}$ $\mathrm{PE}_{\max }$ of $10.6 \mathrm{~lm} \mathrm{~W} \mathrm{~W}^{-1}$, and $\mathrm{EQE}_{\max }$ of $5.1 \%$, respectively. Meaningfully, the devices based on the TAS-CPL strategy displayed higher efficiencies and lower turn-on voltage than those of most conventional fluorescent OLEDs, and their efficiencies roll-off were also lower than those of most OLEDs with TADF emitters [24]. Moreover, the transient EL decay curves were measured (Fig. 6d), revealing clear spike after the voltage was turned off for FLOLEDs, which means significant charge trapping on dopant. In terms of TAS-OLEDs, no charge trapping on dopant was recorded and high ratios of delayed parts of 0.76 and 0.77 for $(P)$ - and $(M)$-HAI, respectively, were observed, evidencing the efficient sensitizing process for enhanced device performances.

CPEL activities of the helicene enantiomer-based OLEDs were investigated as well (Table 1). As shown in Fig. 7, the helicene enantiomer-based TAS-OLEDs displayed intense CPEL activities with opposing $g_{\mathrm{EL}}$ signals. And the $g_{\mathrm{EL}}$ values of the TAS-OLEDs based on $(P)$-HAI and $(M)$-HAI were $-2.3 \times 10^{-3}$ and $+3.0 \times 10^{-3}$, respectively. Moreover, the helicene enantiomer-based FLOLEDs also displayed CPEL activities (Figs S21, S22), and their $g_{\mathrm{EL}}$ values were $-2.2 \times 10^{-3}$ and $+2.3 \times 10^{-3}$, respectively, which were similar to those of TAS-OLEDs. 

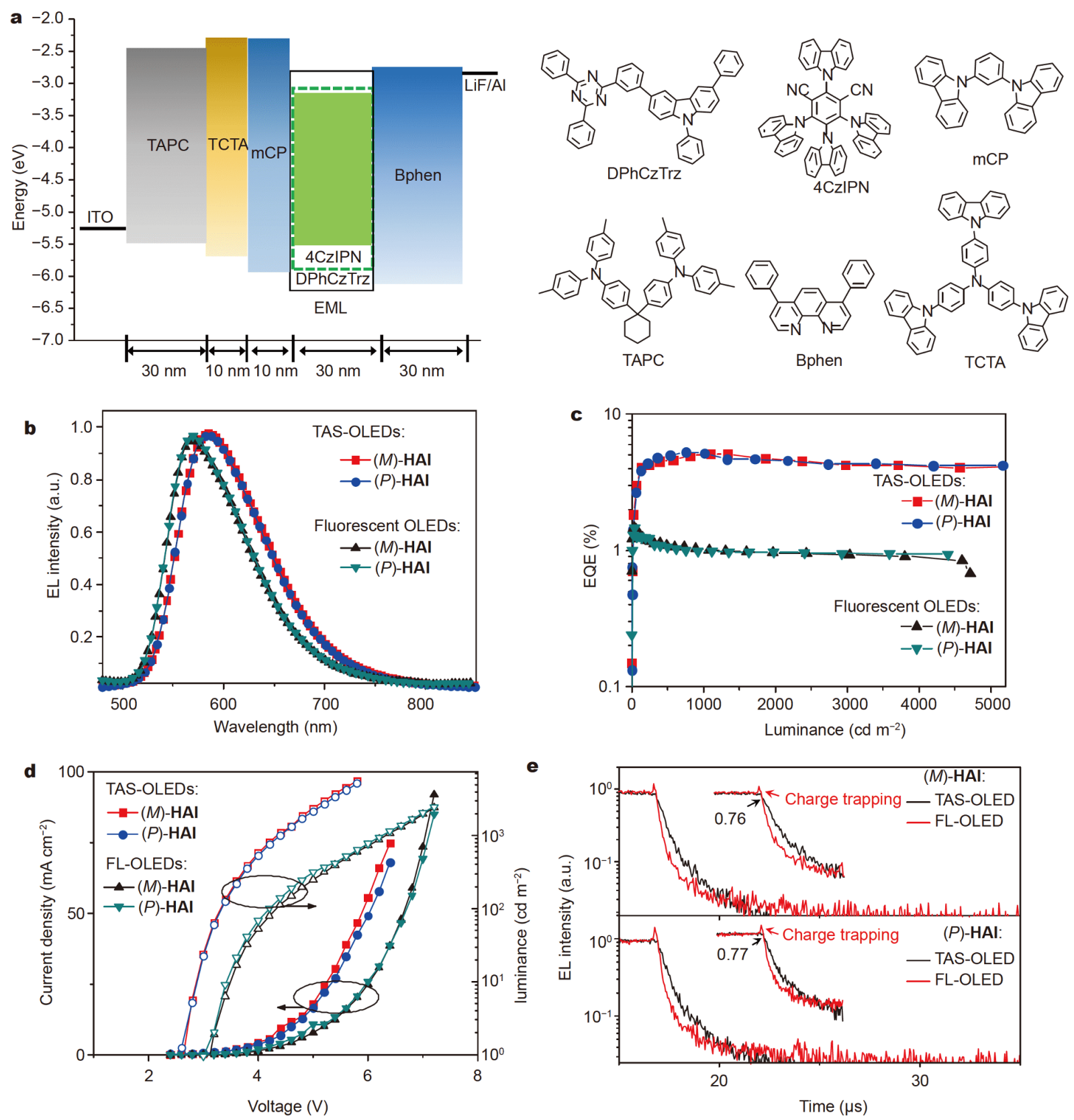

Figure 6 (a) The energy diagram and device structure of the helicene-based OLEDs, and the molecular structures of the compounds used in the device. The EL performance of devices based on (P)-HAI and (M)-HAI: (b) EL spectra (c) EQE-luminance characteristics. (d) Current densityvoltage-luminance characteristics. (e) The transient EL decay curves measured at the corresponding $\lambda_{\mathrm{EL}}$.

The above results indicated that by TAS-CPL strategy, the CP-OLEDs with the helicene enantiomers as emitters can not only significantly enhance the device efficencies, but also obtain intense CPEL with considerable $g_{\mathrm{EL}}$ values.

\section{CONCLUSIONS}

In summary, we have proposed a new strategy of TAS-
CPL for enhancing the efficiencies of fluorescent CPOLEDs by using TADF molecule as sensitizer and chiral fluorophore as emitter. As a result, a pair of helicene enantiomers $(P)$-HAI and $(M)$-HAI with sterically hindered phenyl groups at the $1,1^{\prime}$-positions were synthesized. The enantiomers with rigid helical $\pi$-skeleton had highly thermal and enantiomeric stabilities, and also 
Table 1 EL performances of fluorescent OLEDs and TAS-OLEDs based on helicene enantiomers

\begin{tabular}{ccccccccc}
\hline & $V_{\mathrm{T}}^{\mathrm{e}}(\mathrm{V})$ & $\lambda_{\mathrm{EL}}{ }^{\mathrm{f}}(\mathrm{nm})$ & $\mathrm{EQE}_{\max }$ & $\mathrm{EQE}_{1000}\left(\mathrm{~cd} \mathrm{~m}^{-2}\right)$ & $\mathrm{EQE}_{5000}\left(\mathrm{~cd} \mathrm{~m}^{-2}\right)$ & $\mathrm{CE}_{\max }\left(\mathrm{cd} \mathrm{A}^{-1}\right) \mathrm{PE}_{\max }\left(\operatorname{lm~W^{-1})} g_{\mathrm{EL}}\right.$ \\
\hline $\mathrm{A}^{\mathrm{a}}$ & 3.2 & 570 & $1.2 \%$ & $0.98 \%$ & - & 4.1 & 3.5 & $+2.3 \times 10^{-3}$ \\
$\mathrm{~B}^{\mathrm{b}}$ & 3.2 & 570 & $1.3 \%$ & $1.0 \%$ & - & 4.1 & 3.4 & $-2.2 \times 10^{-3}$ \\
$\mathrm{C}^{\mathrm{c}}$ & 2.8 & 585 & $5.1 \%$ & $5.05 \%$ & $4.1 \%$ & 14.5 & 10.6 & $+3.0 \times 10^{-3}$ \\
$\mathrm{D}^{\mathrm{d}}$ & 2.6 & 585 & $5.3 \%$ & $5.2 \%$ & $4.2 \%$ & 15.1 & 11.3 & $-2.3 \times 10^{-3}$ \\
\hline
\end{tabular}

Fluorescent OLEDs based on a) (M)-HAI and b) (P)-HAI as dopants, respectively, and TAS-OLEDs based on c) $(M)$-HAI and d) $(P)$-HAI as dopants, respectively. e) Turn-on voltage. f) EL peak of devices.

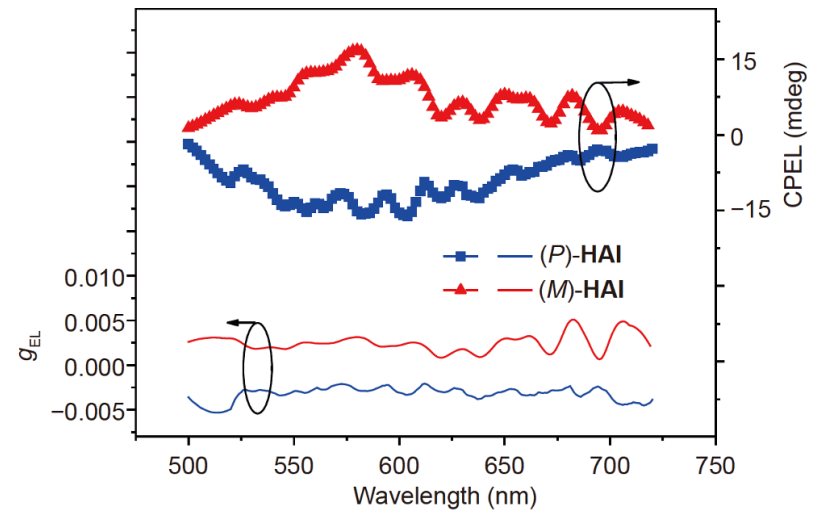

Figure 7 CPEL spectra and $g_{\mathrm{EL}}$ versus wavelength curves of the TASOLEDs based on $(M)$-HAI and (P)-HAI.

dispalyed intense CPL activities with $\left|g_{\text {lum }}\right|$ values of about $6 \times 10^{-3}$. Notably, compared with the devices without TADF sensitizer, the helicene enantiomer-based CPOLEDs with TADF sensitizer not only displayed better performance of lower $V_{\mathrm{T}}$ of $2.6 \mathrm{~V}$, four-fold $\mathrm{EQE}_{\max }$ of $5.3 \%$, and lower efficiencies roll-off of only $1.9 \%$ at $1000 \mathrm{~cd} \mathrm{~m}^{-2}$, but also exhibited intense CPEL with $g_{\mathrm{EL}}$ values of $-2.3 \times 10^{-3}$ and $+3.0 \times 10^{-3}$. This study represented the first TAS fluorescent CP-OLEDs with markedly enhanced efficiencies and intense CPEL. Our new strategy presented herein provides a promising perspective for not only constructing efficient CPEL, but also improving the efficiencies of fluorescent CP-OLEDs, which could greatly promote the development of chiral materials chemistry.

\section{Received 14 July 2020; accepted 14 August 2020; published online 4 November 2020}

1 Zhang DW, Li M, Chen CF. Recent advances in circularly polarized electroluminescence based on organic light-emitting diodes. Chem Soc Rev, 2020, 49: 1331-1343

2 Farshchi R, Ramsteiner M, Herfort J, et al. Optical communication of spin information between light emitting diodes. Appl Phys Lett, 2011, 98: 162508

3 Yang Y, da Costa RC, Fuchter MJ, et al. Circularly polarized light detection by a chiral organic semiconductor transistor. Nat Pho- ton, 2013, 7: 634-638

4 Kim DY. Potential application of spintronic light-emitting diode to binocular vision for three-dimensional display technology. J Korean Phys Soc, 2006, 49: 505-508

5 Peeters E, Christiaans MPT, Janssen RAJ, et al. Circularly polarized electroluminescence from a polymer light-emitting diode. J Am Chem Soc, 1997, 119: 9909-9910

6 Yang Y, da Costa RC, Smilgies DM, et al. Induction of circularly polarized electroluminescence from an achiral light-emitting polymer via a chiral small-molecule dopant. Adv Mater, 2013, 25: 2624-2628

7 Zinna F, Giovanella U, Bari LD. Highly circularly polarized electroluminescence from a chiral europium complex. Adv Mater, 2015, 27: 1791-1795

8 Li TY, Jing YM, Liu X, et al. Circularly polarised phosphorescent photoluminescence and electroluminescence of iridium complexes. Sci Rep, 2015, 5: 14912

9 Brandt JR, Wang X, Yang Y, et al. Circularly polarized phosphorescent electroluminescence with a high dissymmetry factor from PHOLEDs based on a platinahelicene. J Am Chem Soc, 2016, 138: 9743-9746

10 Zinna F, Pasini M, Galeotti F, et al. Design of lanthanide-based OLEDs with remarkable circularly polarized electroluminescence. Adv Funct Mater, 2017, 27: 1603719

11 Han J, Guo S, Wang J, et al. Circularly polarized phosphorescent electroluminescence from chiral cationic iridium(III) isocyanide complexes. Adv Opt Mater, 2017, 5: 1700359

12 Lee DM, Song JW, Lee YJ, et al. Control of circularly polarized electroluminescence in induced twist structure of conjugate polymer. Adv Mater, 2017, 29: 1700907

13 Di Nuzzo D, Kulkarni C, Zhao B, et al. High circular polarization of electroluminescence achieved via self-assembly of a light-emitting chiral conjugated polymer into multidomain cholesteric films. ACS Nano, 2017, 11: 12713-12722

14 Han J, Guo S, Lu H, et al. Recent progress on circularly polarized luminescent materials for organic optoelectronic devices. Adv Opt Mater, 2018, 6: 1800538

15 Wan L, Wade J, Salerno F, et al. Inverting the handedness of circularly polarized luminescence from light-emitting polymers using film thickness. ACS Nano, 2019, 13: 8099-8105

16 Jiang Z, Wang J, Gao T, et al. Rational design of axially chiral platinabinaphthalenes with aggregation-induced emission for red circularly polarized phosphorescent organic light-emitting diodes. ACS Appl Mater Interfaces, 2020, 12: 9520-9527

17 Zhang $\mathrm{Y}$, Zhang $\mathrm{X}$, Zhang $\mathrm{H}$, et al. High green brightness circularly polarized electroluminescence regulated by rigid chiral D-A type emitters. J Phys Chem C, 2019, 123: 24746-24753

18 Zhang X, Zhang Y, Li Y, et al. High brightness circularly polarized 
blue emission from non-doped OLEDs based on chiral binaphthylpyrene emitters. Chem Commun, 2019, 55: 9845-9848

19 Zhang X, Zhang Y, Zhang H, et al. High brightness circularly polarized organic light-emitting diodes based on nondoped aggregation-induced emission (AIE)-active chiral binaphthyl emitters. Org Lett, 2019, 21: 439-443

20 Li M, Lin WB, Fang L, et al. Recent progress on circularly polarized luminescence of chiral organic small molecules. Acta Chim Sin, 2017, 75: 1150-1163

21 Ma JL, Peng Q, Zhao CH. Circularly polarized luminescence switching in small organic molecules. Chem Eur J, 2019, 25: 15441-15454

22 Han J, Yang D, Jin X, et al. Enhanced circularly polarized luminescence in emissive charge-transfer complexes. Angew Chem Int Ed, 2019, 58: 7013-7019

23 Sang Y, Han J, Zhao T, et al. Circularly polarized luminescence in nanoassemblies: generation, amplification, and application. Adv Mater, 2019, 31: 1900110

24 Wong MY, Zysman-Colman E. Purely organic thermally activated delayed fluorescence materials for organic light-emitting diodes. Adv Mater, 2017, 29: 1605444

25 Xu Z, Tang BZ, Wang Y, et al. Recent advances in high performance blue organic light-emitting diodes based on fluorescence emitters. J Mater Chem C, 2020, 8: 2614-2642

26 Imagawa $\mathrm{T}$, Hirata $\mathrm{S}$, Totani $\mathrm{K}$, et al. Thermally activated delayed fluorescence with circularly polarized luminescence characteristics. Chem Commun, 2015, 51: 13268-13271

27 Wang YF, Lu HY, Chen C, et al. 1,8-Naphthalimide-based circularly polarized TADF enantiomers as the emitters for efficient orange-red OLEDs. Org Electron, 2019, 70: 71-77

28 Wang YF, Li M, Zhao WL, et al. An axially chiral thermally activated delayed fluorescent emitter with a dual emitting core for a highly efficient organic light-emitting diode. Chem Commun, 2020, 56: 9380-9383

29 Li M, Li SH, Zhang D, et al. Stable enantiomers displaying thermally activated delayed fluorescence: efficient OLEDs with circularly polarized electroluminescence. Angew Chem Int Ed, 2018, 57: 2889-2893

30 Li M, Wang Y-, Zhang D, et al. Axially chiral TADF-active enantiomers designed for efficient blue circularly polarized electroluminescence. Angew Chem Int Ed, 2020, 59: 3500-3504

31 Song F, Xu Z, Zhang Q, et al. Highly efficient circularly polarized electroluminescence from aggregation-induced emission luminogens with amplified chirality and delayed fluorescence. Adv Funct Mater, 2018, 28: 1800051

$32 \mathrm{Wu} \mathrm{Z}$, Han $\mathrm{H}$, Yan Z, et al. Chiral octahydro-binaphthol compound-based thermally activated delayed fluorescence materials for circularly polarized electroluminescence with superior EQE of $32.6 \%$ and extremely low efficiency roll-off. Adv Mater, 2019, 31: 1900524

33 Wang Y, Zhang Y, Hu W, et al. Circularly polarized electroluminescence of thermally activated delayed fluorescence-active chiral binaphthyl-based luminogens. ACS Appl Mater Interfaces, 2019, 11: 26165-26173

34 Sun S, Wang J, Chen L, et al. Thermally activated delayed fluorescence enantiomers for solution-processed circularly polarized electroluminescence. J Mater Chem C, 2019, 7: 14511-14516

35 Luo XF, Han HB, Yan ZP, et al. Multicolor circularly polarized photoluminescence and electroluminescence with 1,2-diaminecyclohexane enantiomers. ACS Appl Mater Interfaces, 2020, 12:
23172-23180

36 Nakanotani H, Higuchi T, Furukawa T, et al. High-efficiency organic light-emitting diodes with fluorescent emitters. Nat Commun, 2014, 5: 4016

37 Zhang D, Duan L, Li C, et al. High-efficiency fluorescent organic light-emitting devices using sensitizing hosts with a small singlettriplet exchange energy. Adv Mater, 2014, 26: 5050-5055

38 Byeon SY, Lee DR, Yook KS, et al. Recent progress of singletexciton-harvesting fluorescent organic light-emitting diodes by energy transfer processes. Adv Mater, 2019, 31: 1803714

39 Shen Y, Chen CF. Helicenes: synthesis and applications. Chem Rev, 2012, 112: 1463-1535

40 Zhao ZH, Liang X, He MX, et al. Triarylborane-based[5]helicenes with full-color circularly polarized luminescence. Org Lett, 2019, 21: 9569-9573

41 Yan Z, Luo X, Liu W, et al. Configurationally stable platinahelicene enantiomers for efficient circularly polarized phosphorescent organic light-emitting diodes. Chem Eur J, 2019, 25: 5672-5676

42 Maeda C, Nagahata K, Shirakawa T, et al. Azahelicene-fused BODIPY analogues showing circularly polarized luminescence. Angew Chem Int Ed, 2020, 59: 7813-7817

43 Lin WB, Li M, Fang L, et al. Recent progress on multidimensional construction of helicenes. Chin Chem Lett, 2018, 29: 40-46

44 Fang L, Lin W, Shen Y, et al. Applications of helicenes and their derivatives in asymmetric catalysis. Chin J Org Chem, 2018, 38: 541-554

45 Fang L, Lin W, Chen C. Tetrahydrobenzo[5]helicenediol derivatives as additives for efficient proline-catalyzed asymmetric ListLerner-Barbas aldol reactions of bulky aldehyde substrates. Chin Chem Lett, 2018, 29: 1223-1225

46 Zhao WL, Li M, Lu HY, et al. Advances in helicene derivatives with circularly polarized luminescence. Chem Commun, 2019, 55: 13793-13803

Acknowledgements This work was supported by the National Natural Science Foundation of China (21871272, 91956119 and 21521002), the Youth Innovation Promotion Association CAS (2019034), and Qingdao University of Science and Technology (QUSTHX201929).

Author contributions Li M, Zhang D and Chen CF designed the whole study; Li M and Wang YF synthesized the organic compounds; Li $\mathrm{M}$ and Zhang DW characterized the properties of compounds; Zhang D and Li M fabricated and optimized the devices; Li M wrote the paper with support from $\mathrm{Hu}$ ZQ, Duan L and Chen CF. All authors contributed to the general discussion.

Conflict of interest The authors declare no conflict of interest.

Supplementary information Experimental details and supporting data are available in the online version of the paper. 


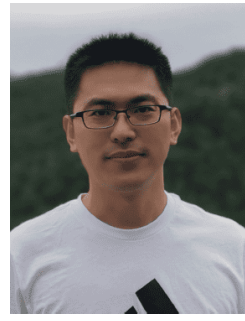

Meng Li received his $\mathrm{PhD}$ from the Institute of Chemistry, Chinese Academy of Sciences in 2015 under the supervision of Prof. Chuan-Feng Chen. He is currently working as an associate professor at the Institute of Chemistry, Chinese Academy of Sciences. His research interests focus on the chiral optoelectronic materials and devices.

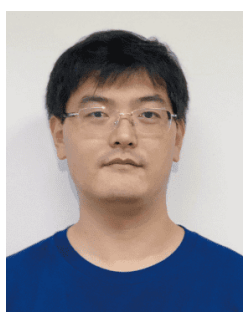

Dongdong Zhang received his $\mathrm{PhD}$ from the Department of Chemistry, Tsinghua University, in 2016, under the supervision of Prof. Yong Qiu and Prof. Lian Duan. Currently he is working at Tsinghua University. His research interests focus on developing new TADF materials as emitters or hosts for high-performance OLEDs.

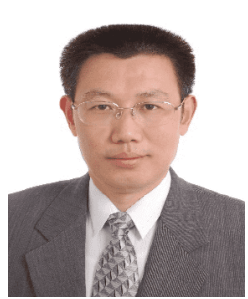

Chuan-Feng Chen has been working as a full professor of organic chemistry at the Institute of Chemistry, Chinese Academy of Sciences since 2001. His current research interests include supramolecular chemistry based on synthetic macrocyclic hosts (helic $[n]$ arenes, pagoda $[n]$ arenes), molecular machines and stimulus responsive supramolecular materials, optoelectronic materials and devices, and helicene chemistry.
热激活延迟苂光材料敏化的螺烯对映体有机发光 二极管: 一种提高电致圆偏振发光效率的新策略

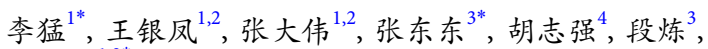
陈传峰 ${ }^{1,2^{*}}$

摘要 为了提高基于手性苂光分子的有机圆偏振发光二极管(CPOLED) 器件效率, 本文提出了一种全新的热激活延迟苂光材料敏 化圆偏振发光(TAS-CPL)的策略. 设计合成了一对具有刚性骨架的 螺烯对映体 $(P)$-HAI和 $(M)$ - HAI作为器件的手性发光客体, 研究发 现螺烯对映体具有高的热稳定性、手性构型稳定性、良好的光物 理性质, 尤其是具有强的 CPL性质, 其荧光不对称因子 $\left(\left|g_{\mathrm{lum}}\right|\right)$ 约为 $6 \times 10^{-3}$. 与直接以螺烯对映体作为发光客体的 CP-OLED相比, 通过 TADF敏化剂热激活敏化螺烯对映体的CP-OLED表现出更低的启 动电压 $(2.6 \mathrm{~V})$ 、更低的效率滚降 $\left(1.9 \%\right.$, 亮度为 $\left.1000 \mathrm{~cd} \mathrm{~m}^{-2}\right)$ 以及增 加四倍的最大外量子效率 $\left(\mathrm{EQE}_{\text {max }}, 5.3 \%\right)$, 螺烯对映体的电致发光 不对称因子分别为 $-2.3 \times 10^{-3}$ 和 $+3.0 \times 10^{-3}$. 这是首例基于热激活延 迟荧光材料敏化圆偏振发光的CP-OLED, 为提高手性荧光分子的 电致圆偏振发光效率提供了有效策略. 